\title{
A simple dialysis device for large DNA molecules
}

$\overline{\text { Samuel JW Krerowicz }}$ 1,2,3,4,6, Juan P Hernandez-Ortiz ${ }^{4,5,6}$ \& David C Schwartz ${ }^{\star, 1,2,3,4,6}$

\section{ABSTRACT}

The potential of genomic DNA is realized when new modalities are invented that manipulate large DNAs with minimal breakage or loss of sample. Here, we describe a polydimethylsiloxane-polycarbonate membrane device to remove small molecules from a sample while retaining large DNAs. Dialysis rates dramatically change as DNA size in $\mathrm{kb}(\mathrm{M})$ increases and DNA dimensions become comparable to pore size, and chain characteristics go from rod-like to Gaussian. Consequently, we describe empirical rates of dialysis, $R$, as a function of $\mathrm{M}$ as falling into two regimes: DNAs $\leq 1 \mathrm{~kb}$ show $R(M)$ $\sim e^{-t / T}{ }_{M}\left(t=\right.$ time, $T_{M}=$ time constant $)$, while DNAs $\geq 1.65$ kb slowly passage with $R(M) \sim M^{1.68}$; such partitioning potentiates single-molecule imaging

\section{LAY ABSTRACT}

To analyze DNA molecules, it is important that little contaminating DNA is present so that it does not drown out the signal of the DNA you are interested in. This paper describes a simple method of filtering out small DNA molecules so that only the large, interesting molecules are left behind. We do so by using filters that have holes of a very precisely defined size so that only DNA smaller than these holes can easily pass through them, leaving behind most of the DNA that is larger than the holes.

\section{METHOD SUMMARY}

To remove small molecules from large DNA analytes, we developed a polydimethylsiloxane dialysis chamber that uses polycarbonate track-etched membranes to size selectively remove small DNA molecules from a sample, while retaining the vast majority of large DNA molecules. Our method provides a procedurally simple way to greatly enrich a sample of large DNA relative to small DNA with minimal breakage or loss of the large DNA.

\section{KEYWORDS}

dialysis • large DNA • polydimethylsiloxane $\cdot$ small DNA - track-etched membranes

'Laboratory for Molecular \& Computational Genomics, UW Biotechnology Center, University of Wisconsin-Madison, USA; ${ }^{2}$ Department of Chemistry, UW Biotechnology Center, University of WisconsinMadison, USA; ${ }^{3}$ Laboratory of Genetics, UW Biotechnology Center, University of Wisconsin-Madison, USA; ${ }^{4}$ UW Biotechnology Center, University of Wisconsin-Madison, Madison, Wisconsin 53706, USA; ${ }^{5}$ Department of Materials \& Nanotechnology, Universidad Nacional de Colombia - Medellín, Medellín, 050034, Colombia; ${ }^{6} \mathrm{Colombia/}$ Wisconsin One-Health Consortium, Universidad Nacional de Colombia - Medellín, Medellín 050034, Colombia; *Author for correspondence:dcschwartz@wisc.edu

BioTechniques 66:93-95 (February 2019) 10.2144/btn-2018-0133
Contemporary genomic investigations require large DNA molecules as starting materials and analytes. Multiple ways of analyzing long, single DNA molecules have been developed to complement contemporary technologies to provide information such as long-range rearrangements [1-3] and haplotypes [4,5]. The use of large DNA is also gaining acceptance for DNA materials research [6] and single molecule DNA-protein interaction experiments $[7,8]$. Because large molecules present unique functionalities and challenges, as large DNA is exploited in novel ways, new methods of manipulation need to be developed to fully plumb the opportunities large molecules present. Several techniques exist to manipulate large DNAs, including microand nano-fluidics approaches $[1,2,9,10]$ and agarose inserts $[3,11,12]$. Here, we present a new modality for large DNAs that allows for the removal of small DNAs ( $<1 \mathrm{~kb}$ ) from large ( $>4 \mathrm{~kb}$ ) DNAs by size-dependent transport through track-etched polycarbonate membranes. These membranes not only have very precisely controlled pore diameters, but are also made of biocompatible materials that do not strongly adsorb large DNAs, unlike cellulosic dialysis membranes. Such cellulosic membrane products are commercially available from G-BIOSCIENCES, Inc. (MO, USA 'Genomic Tube-O-DIALYZERTM') for dialysis of lysates, but these costly devices are not designed for the partitioning of large versus small DNA molecules in dilute, purified samples, as supported by our devices.

A simple dialysis chamber constructed from three polydimethylsiloxane (PDMS) discs tightly seals a DNA solution chamber sandwiched between two Isopore membranes (Figure 1A). PDMS slabs are created using a published protocol for making PDMS devices [1], where the PDMS is poured into a petri dish instead of onto a silicon wafer. Three $\sim 20 \mathrm{~mm}$ diameter PDMS discs cut from PDMS slabs form the dialysis chamber shown in Figure 1A. Before use, PDMS discs are rinsed with distilled water and autoclaved using a 20 min liquid cycle. Two-step assembly first creates an open chamber by placing a track-etched Isopore "w polycarbonate membrane between the inner and outer disc, allowing deposition of a liquid sample. Chambers are then sealed using another membrane and disc. Watertight seals, without adhesives, are achieved by pressing parts together at each step. Assembled chambers, with samples, are dialyzed in 50-ml Falcon tubes with $55 \mathrm{ml}$ of dialysis buffer after filling the chamber's outer holes with buffer prior to submersion. Dialysis at $4^{\circ} \mathrm{C}$ using a LabLine 3D rotator (TX, USA) at $\sim 30$ RPM ensures mixing action, augmented by a small air bubble within the tube traveling end-to-end during rotation (see supplementary online protocol for details).

We investigated the utility of these dialysis chambers to remove small DNAs from large DNAs by size-selective transport through the precisely defined, cylindrical pores of polycarbonate track-etched membranes. A $1 \mathrm{~kb}+$ DNA ladder (Thermo Fisher, MA, USA) mixed with $\lambda$ DNA $(0.1-48.5 \mathrm{~kb}, 32 \mu \mathrm{l}$ total, $\sim 18 \mathrm{ng} / \mu \mathrm{l})$ was dialyzed for $10,20,30$ and $40 \mathrm{~h}$ using $400 \mathrm{~nm}$ diameter pores to determine if the small DNA could be removed from the chamber while retaining the large DNA. All samples were analyzed before and after dialysis by measuring the total amount of DNA present using fluorimetry and the relative amount of each size of DNA by measuring the fluores- 


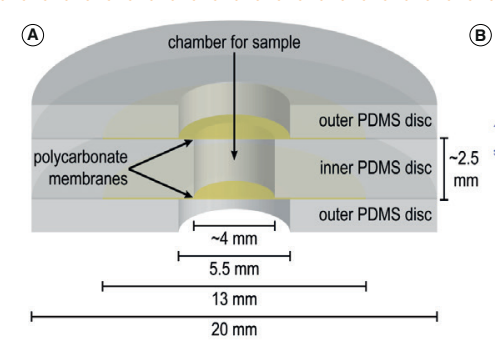

(C)
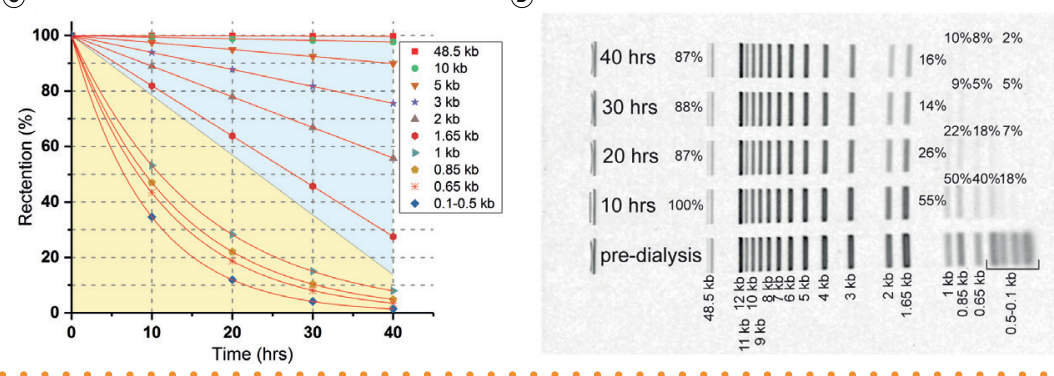

Figure 1. Dialysis chamber assembly, data and analysis. (A) Diagram showing PDMS/Isopore" membrane dialysis chamber assembly. (B) (Left, yellow halftone) Measured concentrations of DNAs $\leq 1 \mathrm{~kb}$ decreased exponentially over time, from which time constants $\left(\mathrm{T}_{\mathrm{M}}\right)$ (Supplementary Figure S1) were extracted, plotted here, and fit by the linear equation: $T_{M}=6.5 \mathrm{~h}+(8.61 \mathrm{~h}) \mathrm{kb}^{-1} \mathrm{M}$; coefficient of determination $\left(R^{2}\right)=0.96$. A median value of $0.3 \mathrm{~kb}$ bulked fluorescence estimates for DNAs sized $0.5-0.1 \mathrm{~kb}$ since discrete values were immeasurable by gel electrophoresis (see $D$ ). (Right; blue halftone) DNA molecules $\geq 1.65 \mathrm{~kb}$ slowly passaged with an apparent linear $\mathrm{R}_{\mathrm{M}}$ (Supplementary Figure S1). $R(M)$ was extracted over this size range $(1.65-48.5 \mathrm{~kb})$ by a log-log plot of the measured rates of dialysis (pmol/h) for DNA, which gave the best fit as: $\mathrm{R}(\mathrm{M})=\left(2.399 \mathrm{E}^{-3} \mathrm{pmol} / \mathrm{h} \cdot \mathrm{kb}\right) \mathrm{M}^{-1.679}$; coefficient of determination $\left(R^{2}\right)=0.98$. (C) Calculated percent retention (the relative amount of DNA of each size remaining in the dialysis chamber after the time specified) given the equations presented in $\mathrm{B}$ of DNA after $10-40 \mathrm{~h}$ of dialysis with $400 \mathrm{~nm}$ pores and assuming equimolar starting concentrations. (D) Image of an agarose gel stained with Sybr Gold with single samples of 10, 20,30 and $40 \mathrm{~h}$ dialysis of a mixture of $\lambda+1 \mathrm{~kb}+$ DNA sizing ladder using $400 \mathrm{~nm}$ pore membranes showing the retention of differently sized molecules at each time point. A gel with triplicate 20 and $40 \mathrm{~h}$ samples can be seen in Supplementary Figure S3. PDMS: Polydimethylsiloxane.

- cence intensity of the bands on an agarose gel using Image J [13].

Doing so, we found that $<10 \%$ of molecules $0.1-0.5 \mathrm{~kb}$ in size remained after $20 \mathrm{~h}$ and that this was reduced even further to $<2 \%$ after $40 \mathrm{~h}$. Even molecules up to $1 \mathrm{~kb}$ in length could be dialyzed away in a nearly quantitative manner ( $5-15 \%$ remaining) after $40 \mathrm{~h}$ (Figure 1D; Supplementary material). Interestingly, while the loss of molecules $\leq 1 \mathrm{~kb}$ in size shows an exponential dependence, above $1 \mathrm{~kb}$ the loss of DNA is linear over the $40 \mathrm{~h}$ tested, with the rate-of-loss highly dependent on the molecule's size (Figure 1B; Supplementary Figure S1; R(M; pmol·hr $\left.\left.{ }^{-1}\right)=0.0024 \cdot \mathrm{M}^{-1.68}\right)$. This apparent transition between exponential and linear passage occurs when the contour length of rod-like DNA approaches and then exceeds the membrane pore diameter of $400 \mathrm{~nm}: 1.0 \mathrm{~kb}$ at $\sim 340 \mathrm{~nm}$, while $1.6 \mathrm{~kb}$ at $\sim 544 \mathrm{~nm}$. Given the controversial accounts of how 'stiff' short DNA is [14] under different mechanical stresses and measurement regimes [15], a detailed understanding of the mechanisms underlying these transition phenomena will require extensive molecular computer simulations and experimental investigation. However, as DNAs become more characteristically Gaussian (polymer chains much longer than their persistence length so they are considered as globular $3 \mathrm{D}$ random walks), at $\sim 3-4 \mathrm{~kb}, \mathrm{R}(\mathrm{M})$ shows a strong power relationship, $\sim \mathrm{M}^{-1.68}$, indicating that the interactions between molecules and membrane pores have likewise changed. The device's partition abilities exploit this power relationship to enhance the retention of large versus small molecules and may even offer a simple means for some enrichment of large coil-like chains without electrophoresis (Figure 1C). Practically speaking, the rate-of-loss for DNA $<4 \mathrm{~kb}$ is too high using $400 \mathrm{~nm}$ pores to be useful and we suggest that these membranes mainly be used to remove molecules $\leq 1 \mathrm{~kb}$ from those $\geq 4 \mathrm{~kb}$ by dialyzing for $20 \mathrm{~h}$, and if a low molar amount of the target molecule is being used (i.e., $<1$ femtomole), we recommend DNA $>12 \mathrm{~kb}$ be used to ensure a high yield of target DNA after $20 \mathrm{~h}$.

As one example, we show the utility of this technique to remove small, unwanted DNAs from the desired large DNA. An excess of Fspl-AlwNI pUC18 fragments $(1.023,0.964,0.699 \mathrm{~kb})$ was dialyzed away from a sample of T7/T4 DNA for $20 \mathrm{~h}$. This sample was imaged both before and after dialysis using standard Optical Mapping techniques [1]. As can be seen in Figure 2, the pre-dialysis sample presents a large amount of small DNA, while that amount is drastically decreased in the 20-h dialysis sample. These experiments, along with a paper that uses these dialysis chambers in three separate steps to self-assemble DNA molecules into microscale objects (unpublished observations), show the utility of these PDMS dialysis chambers to remove small molecules from a sample while retaining the large DNA intact and in high yield.

\section{AUTHOR CONTRIBUTIONS}

SJWK performed all experiments and wrote this paper. SJWK and DCS conceived of the experiments. SJWK, JPHO and DCS analyzed the data. JPHO and DCS supervised the study and edited the manuscript.

\section{ACKNOWLEDGMENTS}

The authors would like to thank Gus Potamousis and Dr. Kristy KounovskySchafer for their training (SJWK) on making PDMS devices.

\section{FINANCIAL \& COMPETING INTERESTS DISCLOSURE}

Work was supported by grants from the National Human Genome Research Institute: NIH R01-HG-367 000225 (DCS) and T32 HG002760 (SJWK). The authors have no other relevant affiliations or financial involvement with any organization or entity with a financial interest in or financial conflict with the subject matter or materials discussed in the manuscript apart from those disclosed.

No writing assistance was utilized in the production of this manuscript.

\section{OPEN ACCESS}

This work is licensed under the AttributionNonCommercial-NoDerivatives 4.0 Unported 
License. To view a copy of this license, visit http://creativecommons.org/licenses/ by-nc-nd/4.0/

\section{SUPPLEMENTARY DATA}

To view the supplementary data that accompany this paper please visit the journal website at: www.future-science. com/doi/suppl/10.2144/btn-2018-0133

\section{REFERENCES}

1. Dimalanta ET, Lim A, Runnheim R et al. A microfluidic system for large DNA molecule arrays. Anal. Chem. 76(18), 5293-5301 (2004)

2. Jo K, Dhingra DM, Odijk T et al. A single-molecule barcoding system using nanoslits for DNA analysis. Proc. Natl Acad. Sci. USA 104(8), 2673-2678 (2007).

3. Gupta A, Place M, Goldstein S et al. Single-molecule analysis reveals widespread structural variation in multiple myeloma. Proc. Natl Acad. Sci. USA 112(25), 7689-7694 (2015).

4. Fan HC, Wang J, Potanina A, Quake SR. Whole-genome molecular haplotyping of single cells. Nature Biotechnol. 29(1), 51 (2011).

5. Zhang $\mathrm{K}$, Zhu J, Shendure $\mathrm{J}$ et al. Long-range polony haplotyping of individual human chromosome molecules. Nature Genet. 38(3), 382 (2006).

6. Watson SMD, Galindo MA, Horrocks BR, Houlton A. Mechanism of formation of supramolecular DNA-templated polymer nanowires. J. Am. Chem. Soc. 136(18), 6649-6655 (2014).

7. Liu J, Hanne J, Britton BM et al. Cascading MutS and MutL sliding clamps control DNA diffusion to activate mismatch repair. Nature 539(7630), 583 (2016).

8. Kim Y, Torre A, Leal AA, Finkelstein IJ. Efficient modifi-

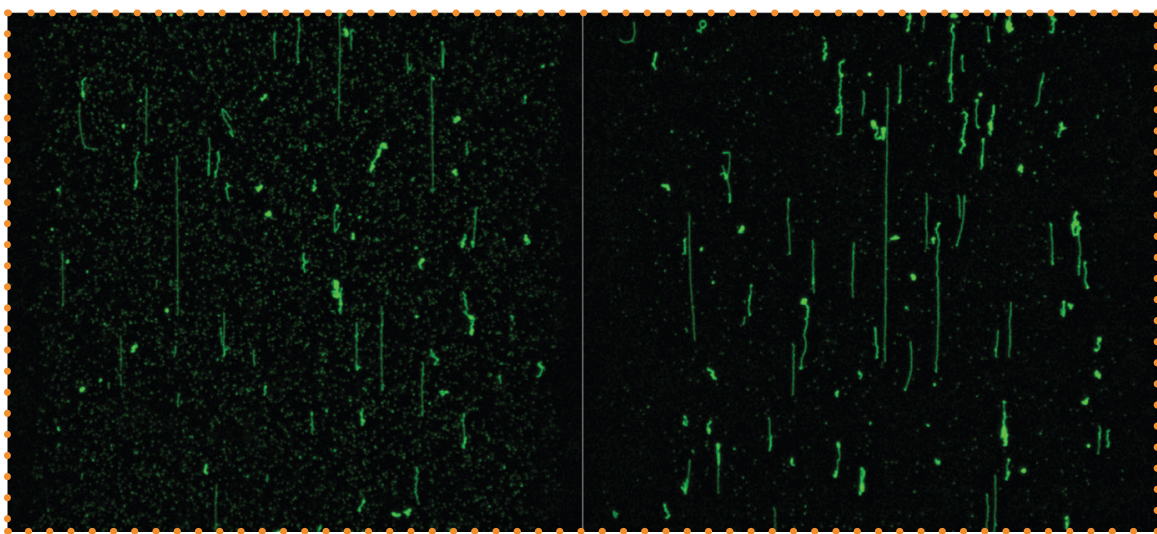

Figure 2. Single-molecule images of T7/T4 + pUC18 digest sample pre-dialysis (left) and after dialysis with 400-nm pore membranes after $20 \mathrm{~h}$ (right). The long molecules are either T4 (165 kb) or T7 (40 kb) while the small green dots prevalent in the pre-dialysis sample and slightly present in the $20 \mathrm{~h}$ sample are the digested pUC18 fragments $(0.7-1 \mathrm{~kb})$. Each panel is $115.5 \times 104.2 \mu \mathrm{m}$.

cation of $\lambda$-DNA substrates for single-molecule studies. Sci. Rep. 7(1), 2071 (2017).

9. Kounovsky-Shafer KL, Hernandez-Ortiz JP, Jo K, Odijk T, de Pablo JJ, Schwartz DC. Presentation of large DNA molecules for analysis as nanoconfined dumbbells. Macromolecules 46(20), 8356-8368 (2013)

10. Kounovsky-Shafer KL, Hernandez-Ortiz JP, Potamousis $\mathrm{K}$ et al. Electrostatic confinement and manipulation of DNA molecules for genome analysis. Proc. Natl Acad. Sci. USA 114(51), 13400-13405 (2017).

11. Schwartz DC, Cantor CR. Separation of yeast chromosome-sized DNAs by pulsed field gradient gel electrophoresis. Cell 37(1), 67-75 (1984).
12. Herschleb J, Ananiev G, Schwartz DC. Pulsed-field gel electrophoresis. Nat. Prot. 2(3), 677-684 (2007).

13. Schneider CA, Rasband WS, Eliceiri KW. NIH Image to Image J: 25 years of image analysis. Nat. Meth. 9(7) 671 (2012).

14. Podgornik R. Polymer physics: DNA off the Hooke. Nat Nanotechnol. 1(2), 100 (2006).

15. Mathew-Fenn RS, Das R, Harbury PAB. Remeasuring the double helix. Science 322(5900), 446-449 (2008).

\section{BioTechniques}

\section{TIME TO RENEW YOUR SUBSCRIPTION}

Subscriptions to BioTechniques need to be renewed every year. Don't miss out on all of the comprehensive reviews, novel research articles, and insightful features found each month in the pages of BioTechniques.

\section{Publishing in 2019}

Tech News Features

Animal Models and

Virtual Reality

Cell culture

Neuroscience

Sequencing

Stem cells

Special Reports

How to transition from

early career to established

Reproducibility

\section{Renew Today and Choose Your \\ Preferred Formats}

\author{
SUBSCRIPTIONS ARE FREE \\ TO QUALIFIED SUBSCRIBERS!
}

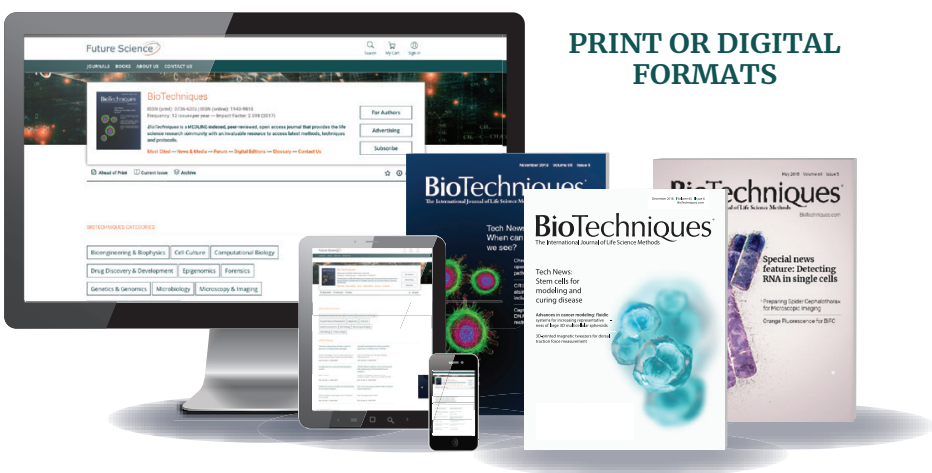

http://bit.ly/BTNrenew 